\title{
Resenha do livro Rio de Janeiro: álbum pitoresco-musical
}

\section{Review of the book Rio de Janeiro: álbum pitoresco-musical}

\author{
LUCAS TAONI ${ }^{\mathrm{a}}$
}
${ }^{a}$ Mestre em História pela Faculdade de Ciências e Letras da Universidade Estadual Paulista "Júlio de Mesquita Filho" (Unesp), campus de Assis.
E-mail: prof.taoni@outlook.com

ALZUGUIR, Rodrigo. Rio de Janeiro: álbum pitoresco-musical. Rio de Janeiro: Edições de Janeiro, 2014.

Patrocinado pela Fundação Nacional das Artes e pela Secretaria Municipal de Cultura do Rio de Janeiro, o livro Rio de Faneiro: álbum pitoresco-musical, de Rodrigo Alzuguir ${ }^{1}$, por intermédio de pesquisa documental e literatura histórica, fez denotar da cidade a cara e inextricável relação entre os sons, as paisagens, as músicas e a construção identitária da cidade. Para os leitores de primeira viagem, a edição chamará muita atenção, uma vez que o livro foi construído de acordo com a sua história e, por isso, está disposto em duas partes que começam cada uma de um lado e encontram-se no meio do encarte, no formato duplo-espelhado. A primeira parte é a recuperação do autêntico Álbum pitoresco-musical, de 1856, antecedida por sete capítulos de Alzuguir sobre tendências urbanas e musicais do Rio de Janeiro oitocentista. Já na segunda parte, há um outro Álbum, inspirado no precursor do século XIX, mas contemporâneo, com compositores e intérpretes que mantêm com o Rio de Janeiro relações topofílicas².

A primeira metade, que remete ao antigo Álbum de 1856, convida os leitores para uma experiência de imersão na vida privada e cultural do Rio de Janeiro. Assim, inicia-se o Capítulo 1, "Um sarau”, em crônica que expõe uma anedótica porém típica confraternização da alta

1 Autor também da premiada biografia (segundo lugar na categoria de Biografias do Prêmio Jabuti 2014) Wilson Batista: o samba foi sua glória (ALZUGUIR, 2013).

2 A palavra "topofilia" é um neologismo, útil quando pode ser definida em sentido amplo, incluindo todos os laços afetivos dos seres humanos com o meio ambiente material, que diferem profundamente em intensidade, sutileza e modo de expressão (TUAN, 1975, p. 136). sociedade e da burguesia carioca, em salão dançante, ao som do piano, iluminação à gás, burburinho da juventude, namoricos modestos, bulício dos sapatos e dos tamancos castigando o verniz do assoalho amadeirado. Explorado textualmente, o estilo musical reinante nos salões da época: a polca. A crônica de Alzuguir (2014, p. 4), aliás, foi inspirada e recontada a partir da música "Tome polca!", dos compositores José Maria de Abreu e Luiz Peixoto, interpretada pela cantora Marlene um século depois. De evidente importância, a polca é um tipo de música que se faz em compasso binário, pulsional, com andamento vivo e acompanhamento rítmico-harmônico colocado nos contratempos. Inquieta, logo se espalhou pelos salões da Europa e, nos anos 1840, atravessou o oceano e chegou às Américas retumbante (ALZUGUIR, 2014, p. 4). José Miguel Wisnik (2004, p. 31), sobre isso, assinalou que "entre o ragtime e o rock'n'roll tudo é polca!". A polca, por assim dizer, é o protótipo de todos os gêneros e ritmos dançantes que no Brasil iriam se capilarizar entre as últimas fases do Segundo Reinado e durante o século XX, dos quais o samba é também herdeiro e o representante proeminente na música popular, atrelado mais tarde aos símbolos da identidade nacional (CUNHA, 2004).

A polca inaugurou definitivamente o mercado da música para danças, absorvido mais tarde pela indústria cultural, acompanhando intimamente as implicações da formação da sociedade de massas, mais nítida nas capitais do país, acirrando a disputa por espaços que havia entre a música de concerto e a música popular, uma vez que os públicos, os músicos e os próprios instrumentos envolvidos poderiam servir a um repertório ou outro com versatilidade, sobretudo no caso das poucas prensas de partituras para piano existentes no Brasil. 
No Capítulo 2, "Pianópolis", estabelece-se a correlação entre a dinâmica econômico-política da capital e a música carioca. Parafraseando o historiador Capistrano de Abreu, Rodrigo Alzuguir assinala que, quando saiu das prensas o Álbum pitoresco-musical, vivia-se um tipo de clímax imperial. Durante um período de quase duas décadas, entre 1850 e o findar da década seguinte, a alta do café, a proliferação de algumas estradas de ferro conectando o Rio a províncias alhures, a adoção e a ampliação do telégrafo, novas normas parlamentares outorgadas no poder e avanços da ciências e das artes, o Rio assistiu a anos de um brilhantismo sem precedentes - ainda que, com efeito, o trabalho escravo e cativo dos africanos estivesse em vagaroso processo de abolição. Na cena musical, metamorfoses de grande impacto também ocorreram, sobretudo com a música profana tomando o lugar consagrado da música sacra: "Os teatros da cidade tremiam sob o impacto dos dós de peito dos tenores e dos agudíssimos das primas donnas, e o chão dos salões familiares eram riscados pelos pés dos casais que saracoteavam ao som das danças europeias" (ALZUGUIR, 2014, p. 10).

No mesmo sentido, é sintomático perceber que, no ano em que o Álbum pitoresco-musical foi impresso, Manuel de Araújo Porto-Alegre, pintor, escritor e político, sucessor direto e aluno de Debret, colocou no Rio de Janeiro o feliz apelido de Pianópolis, a Cidade dos Pianos, tamanha era a devoção e adoração dos cariocas ao instrumento, que multiplicava-se como nunca antes, gerador de música e entretenimento, marcador de prestígio social para músicos, famílias e instituições (ALZUGUIR, 2014, p. 10).

O Capítulo 3, "O álbum", trata da gênese do documento pioneiro por reunir músicas dedicadas à capital. No dia 20 de agosto de 1856, o Correio Popular Mercantil trouxe os detalhes do requinte editorial do álbum para os padrões da época: cada partitura estava acompanhada de uma exclusiva litogravura de Joseph Martinet, endossando imageticamente a ideia de que a música feita em homenagem ao bairro, na verdade, era um exercício de composição incitado pela inspiração paisagística dos bairros, numa interface indissociável de imagem e som e identidade.

Todo o documento reiterava paulatinamente a relação íntima entre o espaço carioca e a música carioca, aliás, contendo oito litogravuras, uma para cada composição, e uma da Baía da Guanabara na capa do artigo de luxo. O Álbum foi confeccionado na rua dos Ourives, número 60 , onde estava instalada em meados do século XIX uma das mais notáveis imprensas de partituras do Brasil, na casa dos Sucessores de Pierre Laforge. A empresa de partituras anunciou em toda a imprensa carioca o lançamento de um artigo musical especialmente luxuoso, este álbum de sete partituras (que poderiam ser adquiridas em conjunto ou avulsas) contendo composições para piano em homenagem a cinco vistas cariocas (Botafogo, Glória, Jardim Botânico, São Cristóvão e Tijuca) e duas dos arrabaldes (Boa Viagem e Petrópolis).

No Capítulo 4, "Da polca ao choro", Alzuguir estrategicamente dedicou-se à dinâmica de grande amálgama das artes que vieram de além-mar, pois, no começo da influência da música europeia nos trópicos, a execução era mantida na sua forma original, todavia, a partir de meados do século XIX, dessa música alienígena, pouco afeita também à nossa disposição com as coisas sincréticas de cultura e arte, iniciou-se um processo irreparável de adaptação, de climatização tropical, de "abrasileirar-se". Muito por causa disso, também, por volta da década de 1870 surgiu no Rio de Janeiro o choro, ou "chorinho", ainda que não propriamente como um gênero musical com balizas tão sólidas como a valsa, o fado ou a sonata, mas dotado de uma idiossincrática brasileirice de reproduzir ao timbre de instrumentos boêmios o repertório da música europeia do Oitocentos, valsas, polcas, schottisches. Por exemplo, aponta David Appleby (1967) em The music of Brazil que o processo gradual de transformação da música europeia em música brasileira, sendo a primeira a matéria-prima e a segunda um produto novo, específico, já era flagrante em Rio de Janeiro: álbum pitoresco-musical. Como primeiro exemplo, Appleby destaca a polca "Glória", de Eduardo Ribas, que embora contivesse fragmentos rítmicos da vibrante polca europeia, já apresentava um quê de "langor tropical", sugerido pela indicação de molto espressiwo (muito expressivo, vagaroso, suave) inscrita na pauta após a introdução dos primeiros compassos (ALZUGUIR, 2014, p. 18).

O Capítulo 5, "Laforge", sobre o músico e empresário Pierre Laforge, aborda o embrião institucional que, mais tarde, viabilizaria a iniciativa do Álbum pitoresco-musical. Pierre Laforge era músico de formação, oboísta e flautista. Chegou ao Rio de Janeiro em 1816, praticamente na mesma leva que trouxe para o Brasil um conjunto especial de artistas e pensadores franceses em em 1815. Graças à derrocada de Napoleão, e à consequente reaproximação diplomática entre Portugal e França, desembarcaram no Rio grandes personalidade europeias, como Taunay, Grandjean de Montigny,Jean-Baptiste Debret e este homem com ideias irreverentes e prestígio crescente, Pierre Laforge, nomeado o flautista oficial da Real Câmara, a célebre instituição musical responsável pelas celebrações religiosas assistidas pela Família Real. Curiosamente, as razões da consagração de Laforge enquanto oficiante da música Real são inexatas, bem como é obscura a crise que a sucedeu, pois, com o findar da relativa 
calmaria na vida carioca em 1831, articulada à abdicação de Dom Pedro I, a vida de Laforge mudou radicalmente de itinerário. Sem imperador e carente de fundos, a Imperial Capela - antiga Real Capela - foi extinta por ordem superior do ministro dos Negócios da Justiça (Manuel José de Souza França), restando a Laforge, do dia para a noite, dedicar-se a quaisquer outras atividades profissionais. Até que, em 1834, o músico pôs em prática uma ideia incomum: fundar uma estamparia com imprensa de música, originalmente localizada na rua do Ouvidor. Houve, é claro, durante o período que remonta à transmigração da Corte e o início do Segundo Reinado, outras iniciativas anteriores a sua, todavia esporádicas, efềmeras, malsucedidas. Ao que tudo indica, Pierre Laforge foi o primeiro a conseguir se estabelecer efetivamente no Rio de Janeiro com uma imprensa de música, até vendê-la à Salmon e Cia. em 1853, empresa que rebatizou o legado de Laforge, contudo conservando-o: daí o nome "Sucessores de Pierre Laforge" impresso em letras garrafais na capa do Álbum de 1856.

O Capítulo 6, "Martinet", trata do prestígio artístico de Joseph Alfred Martinet no Rio de Janeiro e sua contratação para ilustrar o projeto Pitoresco-musical ("pitoresco", "pictórico", ou seja, aquilo que é digno de produção de imagem, vide a natureza atlântica carioca, esfuziante) da casa de partituras dos Sucessores de Pierre Laforge. Continuador de uma linhagem privilegiada, Martinet soube dosar bem o talento com o trabalho e, com essa alquimia, ainda jovem, pôde colher os resultados de um reconhecido artista no Rio de Janeiro, famoso pelos retratos, pelas pinturas e pelas aulas que ministrava na sua própria casa. Martinet desenvolveu também a técnica em litogravura, inaugurando em 1855 sua oficina. Dali em diante, atuou muito sob encomenda, com ilustrações para o tão citado Almanaque Laemmert, retratos litografados de Gonçalves de Magalhães em A Confederação do Tamoios, de Dom Pedro I para a capa da partitura do hino "O brado do Ipiranga" e as não menos importantes oito litogravuras de Rio de Janeiro: Álbum pitoresco-musical (ALZUGUIR, 2014, p. 23).

O Capítulo 7, "Os sete", último capítulo da parte antiga do Álbum pitoresco-musical, retrata passagens biográficas e artísticas dos sete compositores - compositores letrados, são eles também os escritores das músicas na pauta: Demétrio Rivero, Eduardo Ribas, Salvador Fabregas, Geraldo Horta, Quintino dos Santos, J. J. Goyanno e A. Campos. Vencida a última página dos sete compositores, os leitores são presenteados com a reprodução exata do autêntico, antigo e primeiro Rio de Faneiro: álbum pitoresco-musical da casa de partituras dos Sucessores de Pierre Laforge. Trata-se, sem dúvida, de uma consciência patrimonial e democrática acerca da história do Brasil, pois, até então, um exemplar deste álbum estava para a raridade de uma mosca branca.

No outro lado do livro, girando-o em 180 graus, há a segunda versão, o lado contemporâneo, que se conecta com o século XIX pela essência que desde aquela ideia pioneira pôde, através de Rodrigo Alzuguir e um time consagrado de músicos, ser preservada. A relação do Rio de Janeiro com a música: Cristóvão Bastos compôs um tango para Marechal Hermes; Itamar Assiere, uma bossa-nova para o Flamengo; Francis Hime foi pela tradição, e ao bairro da Gávea dedicou uma modinha; Maria Teresa Madeira fez um choro para a Lapa; há ainda outro choro, de Maíra Freitas, dedicado ao Centro; Delia Fischer, em homenagem a Copacabana, compôs um funk carioca, executado ao piano também; e, por fim, o maestro Gilson Peranzzetta homenageou Braz de Pina com um choro lento.

Além disso, o novo Álbum não deixou esquecido o lado pitoresco da cidade: o pintor e desenhista Guilherme Secchin foi convidado a ocupar o lugar de Martinet. Esse time é, portanto, o time dos sucessores dos Sucessores de Pierre Laforge, conectados pelo fascínio que têm pelo Rio, em um arco histórico de um século e meio, que continuará a inspirar compositores, escritores, desenhistas, dramaturgos, amantes da arte e amantes da cidade, construtores de identidade.

\section{REFERÊNCIAS}

ALZUGUIR, R. Wilson Batista: o samba foi sua glória. Rio de Janeiro: Casa da Palavra, 2013.

ALZUGUIR, R. Rio de Janeiro: álbum pitoresco-musical. Rio de Janeiro: Edições de Janeiro, 2014.

APPLEBY, D. The music of Brazil. Texas: University of Texas Press, 1967.

\section{CUNHA, F. L. Da marginalidade ao estrelato:} o samba na construção da nacionalidade (1917-1945). São Paulo: Annablume, 2004.

TUAN, Y.-F. Topofilia: um estudo da percepção, atitudes e valores do meio ambiente. Tradução Lívia de Oliveira. Londrina: Eduel, 2012.

WISNIK, J. M. Sem receita: ensaios e canções. São Paulo: PubliFolha, 2004. 